\title{
Research on New Urbanization in Jilin Province
}

\author{
Yinghua $\mathrm{Yu}^{1,2}$, a
}

${ }^{1}$ Economic and Business School, Jilin Institute of Chemical Technology, Jilin 132022, China;

${ }^{2}$ Business School, Jilin University, Changchun 130012, China.

acherry_yyh@163.com

Keywords: New urbanization; household registration system; ecological construction; entrepreneurial mechanism.

\begin{abstract}
Urbanization is the process accompanied by the development of industrialization and non-agricultural industries to urban agglomeration. It can effectively promote the development of industrialization as well as agricultural modernization. Concept of new urbanization emphasizes on human-centered principle and adheres to the high quality of urbanization. This paper, based on Jilin province urbanization development characteristics, analyzes the status of the construction of new urbanization in Jilin province and existing problems, and discusses some countermeasures. To accelerate the construction pace of new urbanization in Jilin province, we need to optimize the industrial structure, deepen the household registration system reform, accelerate the ecological construction and promote the entrepreneurial mechanism for rural migrant workers in cities, which are conductive to achieving the goal of sustainable development in Jilin Province.
\end{abstract}

\section{Introduction}

Urbanization is closely linked to industrialization and also promotes the modernization of agriculture. It is a basic problem in the process of modernization in China, and an important strategic choice to realize the modernization of our country. According to the plan released by the eighteenth national congress of the Communist Party of China, urbanization construction is a strong engine for sustainable and healthy economic growth in the next 10 to 20 years. In the passing years from the reform and opening up, China's urbanization has achieved rapid development, and urban living environment has been significantly improved. In 2011, China's urban population exceeded the rural population for the first time, and entered a new era of urban society as the main body[1]. To Jilin province, according to its agricultural characteristics, construction of new urbanization has special strategic significance. How to design the path of new urbanization has been widely discussed and still needs to be further studied. And first of all, the connotation of new urbanization needs to be clarified.

\section{Connotation of new urbanization}

The concept of urbanization originated in Britain and America. In 1980s, Chinese scholars quoted concepts from urban geography and planning areas to interpret China's urbanization. It is considered that the urbanization is accompanied by the development of industrialization, non-agricultural to urban agglomeration, urban population concentration, increasing number of towns, and continuous expansion of cities and towns, and it continues spreading to the countryside,[2]Charactering in upgrade of industrial structure as well as change of regional landscapes[3]. "New urbanization" is proposed on the basis of "urbanization", emphasizing to the people's livelihood and sustainable development. The connotation of new urbanization perceives the pursuit of equality, happiness, transformation, green, health and intensive as the core target, and achievement of coordination of various regional and industrial upgrading, low carbon transition, ecological civilization and the intensive and efficient, system reform and system innovation as focus and content of new process[4].Premier $\mathrm{Li}$ Keqiang repeatedly stressed that new urbanization is "human-centered", goal of which is to make people's lives better. Thus "human-centered" is the most basic and important characteristic of new urbanization. 


\section{New Urbanization Status in Jilin Province}

Jilin province is one of the areas where the development of urbanization is faster and earlier. In 2014, the resident population of Jilin Province was 27.52million, and the urban population was 15.09 million, the urbanization rate reached $54.81 \%$.After many years of construction and development, the status of new urbanization in Jilin province are showed below:

\subsection{Urbanization rate}

Jilin province is a major agricultural province, and the urbanization rate has been higher than the national average for many years. But at the same time, Jilin Province urbanization rate increases slowly, in nearly five years, an average increase of only 0.9 percent, significantly lower than the national average urban rate of 7.1 percentage points. At the same time, compared with the national average, the pace of urbanization in Jilin province has begun to slow down, which may indicate it is in the stage of peak period of urbanization development.

\subsection{Quality of urbanization}

The concept quality of urbanization, refers to the constituent elements of the quality development, coordination degree and propulsive efficiency[5]. On March 12th, 2013, "China Economic Weekly" published the "China Urbanization Quality Report", which selected 286 sample cities. In the top 100 , Jilin province accounted for only 3 seats, and also ranked only 67 (Songyuan), 68 (Changchun) and 95 (Jilin), which indicated Jilin Province urbanization quality was only in the national average or below. At the same time, as of the end of 2013, the urbanization rate of Jilin province ranked thirteenth in the country's 31 Provinces. The difference of the two rank numbers shows that there must be some factors that set off the coordination in the process of urbanization development in Jilin Province, which also influences the quality of the development of urbanization.

\subsection{Income gap between urban and rural residents}

In recent years, with the development of economy, the income of urban and rural residents of Jilin Province also continues to increase, between 2009 and 2013, urban residents, people can be disposable income net increase 8269 yuan, an average annual increase of 12.11\%; annual per capita net income of rural residents net increase of 4355 yuan, an average annual increase of $46.78 \%$. In 2009, the income of urban residents is 2.66 times that of rural residents. In 2013, this figure dropped to 2.31.If only view the numerical value, the income gap between urban and rural residents was decreased, but more than 2 ratio times was still a big gap. And the gap between urban and rural residents' consumption tendency is not large, maintained at around $70 \%$.

\subsection{Industrial structure}

Jilin province is an important industrial and grain production province in China. Automobile, petrochemical, agricultural processing are the three pillar industries. In the past 5 years, the three major industries of Jilin province developed rapidly. Only in 2013, the first industrial added value of $4 \%$; the second industry of $8.8 \%$; the third industry $8.7 \%$. During 2009-2013, the proportion of the first industry only slightly higher than the national average value. But there was still a large gap between the figure of third industry. Industrial structure of Jilin Province is still necessary to further optimized.

\section{Existing problems for new urbanization development in Jilin Province}

\subsection{Unreasonable urban system structure}

From the latest census(2010) data, the urban population of the two mega cities (Changchun and Jilin) accounted for 39.53\% of the total urban population of Jilin Province, and the 6 medium-sized cities accounted for $23.43 \%$, the rest $37 \%$ urban population living in small cities and small towns. Radiation and driving ability of large and medium cities is not strong enough, which restricts the development of new urbanization in Jilin Province.

\subsection{Relatively large agricultural population proportion}

Jilin province is a major agricultural province in China, with a large number of agricultural populations. On one hand, new urbanization drives the population gathering in city, on the other hand, non-farming economy in city should be able to absorb these rural labors. But the number of 
employees and the proportion of GDP are not coordinated in the three major industries. In particular, the first industry still has a large number of labors needed to transfer to other industries, which could optimize the industrial structure as well as promote the new urbanization.

\subsection{Risk of lacking sustainable development capacity}

A core theme of the new urbanization is the green urbanization, advocating intensive, smart, green and low-carbon life. Jilin province, the northeast old industrial base, has automobile, petrochemical, pharmaceutical as its pillar industries. Despite economic development and thus absorbing a large number of labors, its development has experienced high energy consumption, high pollution, high emission process. The promotion of new urbanization means a large number of floating rural people. Two and three industries in the city ought to absorb these populations. But at the same time we cannot ignore the ecological carrying capacity of the city. The emergence pollution caused by more industrial production and more urban population will make the city in a difficult situation. Although in Jilin Province has promoted low carbon economy and circular economy in the petrochemical, pharmaceutical and other industries, however, problems arising in the process of urbanization promoting still cannot be ignored.

\subsection{Institutional mechanism barriers}

For a long time, rural population transferring in Jilin province has been restricted to the difference of household registration systems. With the accelerated process of social transformation, the number of the floating population is increasing. The difference between urban and rural areas in the household registration system has caused a lot of social problems: employment, welfare, education, health care, as well as public investment and so on. There needs a relative balance in institutional mechanism or the barriers will restrict the development of new urbanization in Jilin province.

\section{Countermeasures for new urbanization in Jilin Province}

According to the characteristics and existing problems, effective way to accelerate the construction of new urbanization in Jilin province includes following aspects such as industrial structure, ecological construction, system reform and entrepreneurial mechanism.

\subsection{Industrial structure needs to be further optimized}

The purpose of new urbanization is to allow residents to live and work in peace and contentment in the town. Urbanization must be supported by industry, with the motivation of new industrialization to promote the coordinated development of the industries, and to create more jobs through industrial development. In fact, the adjustment between industrial structure and development of urbanization has a mutual promotion relationship. The optimization of industrial structure will lead to changes in employment, and urbanization will thus be further promoted[6]. For Jilin Province, industrialization of agriculture is the premise to accelerate the rapid development of new urbanization. The core problem of agricultural industrialization is to release the peasants from the land, and then they become the new labor supply of urban economic development. Government constantly improves the living standards of rural residents, and promotes the transfer of rural population to cities and towns. On the other hand, the central cities and towns should also actively improve the investment environment of industrial development, and provide a good living space for the agricultural processing industry.

\subsection{Reform of the household registration system needs to be further deepen}

The advancement of urbanization involves a lot of social problems. For farmers, only to fully protect their lives will they spontaneously take the initiative into the city. Whether farmers can be satisfied, the core problem lies in weather the two household registration system between urban and rural residents could be completely eliminated, which has been a long and arduous task for reform of the system. On July 30, 2014, State Council put forward" on further promote reform of the household registration system”, in which the establishment of a unified urban and rural household registration system, further adjustment account migration policy, and expansion the coverage of basic public services will be built. The government of Jilin Province in 2010 issued the reform of the household registration management system, which provides the application conditions settled in Changchun and Jilin, prefecture level cities, and county-level cities. Needless to say, the reform of 
the household registration system in Jilin provinces has been a great success, but in the province wide range it still needs more distinctive reform efforts. For example, Changchun and Jilin City can absorb experience from other big cities and control migrant population reasonably and orderly; other medium-sized cities can release the registration and increase city radiation ability. When the agricultural population meeting the transfer conditions settled in the town, without worrying about social security and welfare benefits problems such as housing, health care and pension due to household registration systems, then the agricultural population does enjoy the benefits of urban life, which will improve their belonging and happy feeling.

\subsection{Ecological construction needs to be further accelerated}

New urbanization needs harmony between human and nature. Low carbon design, green production and consumption, and the concept of ecological civilization need to be lead into the construction of urbanization. And people need to be guided to establish friendly environmental ideas in order to ensure the harmonious development. Jilin province is the second ecological province in China. Changbai Mountain is an important water source in the northeast region, and its forest ecosystem is also an important ecological barrier in Jilin province. In eastern part of Jilin Province, development of new urbanization should pay special attention to the ecological protection. And in western region, due to the lack of natural precipitation coupled with the destruction of human factors, in recent years, ecological function has declined. Desertification and salinization phenomenon have become increasingly serious. In the development of ecological agriculture, the emphasis in the western regions should be placed on the management of deterioration of the ecological environment, strengthening the construction of returning farmland to forests and restoring vegetation. Only through the ecological construction and establishment of a strong ecological barrier could Jilin Province be sustainable development and promote the process of urbanization in the central region further.

\subsection{Entrepreneurial mechanism for rural migrant workers needs to be further promoted}

In Jilin Province, a large number of farmers work outside homes. And if this part of the workers could return home, it will be an important driving force to promote new urbanization. Entrepreneurial economy is considered to be the fourth element of productivity. As the State Department vigorously promoting "public entrepreneurship and innovation," rural migrant workers could return home and start business. They have worked outside and have seen the economic prosperity of big city. They appreciate the value of special industries in their hometowns. If they have entrepreneurial willing, migrant experience will certainly trigger their entrepreneurial behavior. To further optimize entrepreneurial environment, government needs to strengthen policy guidance, enhance the entrepreneurial intention, inspire the spirit of entrepreneurship, increase the intensity of tax policy and financial support, improve the business environment and professional infrastructure, develop entrepreneurial education and training, improve the transfer of rural labor force entrepreneurial ability, and guide the rural transfer to the entrepreneurship, etc.[7,8]. At present, the nationwide "Young Farmer" program has been lead in Jilin Province. It provides professional business mentor training and mentoring entrepreneurial programs to the rural, which has already played a certain effect, but the coverage still needs to be further improved.

\section{Conclusion}

Urbanization is the process that can effectively promote the development of industrialization and information technology, as well as the process of agricultural modernization. Concept of new urbanization emphasizes people-oriented principle and adheres to the high quality of urbanization. This paper analyzes the status of the construction of new urbanization in Jilin province and existing problems, and discusses countermeasures. To accelerate the construction pace of new urbanization in Jilin province, we need to optimize the industrial structure, deepen the household registration system reform, accelerate the ecological construction and promote the entrepreneurial mechanism for rural migrant workers in cities, which are conductive to achieving the goal of sustainable development in Jilin Province. 


\section{References}

[1]. Congjun Li, China's new urbanization strategy, Beijing: Xinhua Publishing House,2013.(In Chinese)

[2]. Kai Ma,"Change the way of urbanization development and improve the quality of urbanization development under a path of Chinese urbanization”, Journal of china national school of administration, vol. 5, pp.4-12,2012.(In Chinese)

[3]. Shimou Yao and Fengxuan Xue, "Major Strategic Issues to promote the healthy development of urbanization in China”, Urban Insight, vol. 23, pp.5-15,2013.(In Chinese)

[4]. Chenghua Li,"New urbanization strategy under the guidance of scientific concept of development”, Seeing Truth, vol. 14, pp.35-37,2012.(In Chinese)

[5]. ]Borong Li, China Urbanization Model Report, Beijing: National School of Administration Press,2013. (In Chinese)

[6]. Lina Zhang and Jia Xu, "Thoughts on Enhancing the quality of urbanization in Jilin Province ”, Xinchangzheng,vol.7,2013.(In Chinese) 